\title{
Supply chain coordination under retail competition and advertising dependent demand
}

\author{
Mehdi Mirzaee*, Ahmad Makui and Ebrahim Manzari Tavakoli
}

Department of Industrial Engineering, Iran University of Science \& Technology, Tehran, Iran

\begin{tabular}{|c|c|}
\hline A R T I C L E I N F O & A B S T R A C T \\
\hline $\begin{array}{l}\text { Article history: } \\
\text { Received } 1 \text { June } 2011 \\
\text { Received in revised form } \\
\text { November, 26, 2011 } \\
\text { Accepted } 14 \text { December } 2011 \\
\text { Available online } \\
\text { 3 January } 2012 \\
\text { Keywords: } \\
\text { Supply chain coordination } \\
\text { Advertising cost sharing contract } \\
\text { Quantity discount contract } \\
\text { Retail competition }\end{array}$ & $\begin{array}{l}\text { Supply chain coordination as an effective tool plays an important role in improving supply } \\
\text { chain performance. In this article, a two-level supply chain with one manufacturer and two } \\
\text { retailers is considered. The order quantity that retailers are faced with depends on the amount of } \\
\text { advertisements and both retailers compete with each other on advertising. The Stackelberg } \\
\text { game is established between manufacturer and retailers such that the manufacturer and the } \\
\text { retailers play the leader and the follower roles, respectively. First, the manufacturer determines } \\
\text { the wholesale prices for retailers and instead, the retailers determine the order quantity and } \\
\text { advertising level, simultaneously. The manufacturer produces one kind of product and delivers } \\
\text { it to retailers before the beginning of selling season. Retailers can affect the order quantity } \\
\text { regarding the demand dependency on advertising level through the incurred costs from the } \\
\text { advertising. In this paper, we show that we can achieve the desirable supply chain coordination } \\
\text { through using combined quantity discount and advertising cost sharing contracts. We also } \\
\text { consider the win-win situation for all the members of the supply chain. }\end{array}$ \\
\hline
\end{tabular}

(C) 2012 Growing Science Ltd. All rights reserved

\section{Introduction}

Today, there are growing challenges on business environment because of increase in competition and customer expectations. Therefore, in this situation companies should have a good flexibility to respond to new market requirements, achieve the highest profit from opportunities, and suffer the lowest possible losses from threats (Hosseini, 2008). Two well-known tools for improving competitiveness in the supply chain are integrating organizations and creating coordination among material flows, information and capital. Therefore, to overcome these obstacles, setting the orientation of goals and accelerating the flows among supply chains are common issues in this context.

In decentralized supply chains, each chain member is first concerned about optimizing its goals and in this condition; there might be some conflicts between these goals, which can reduce the performance of supply chain. Therefore, coordination plays an important role in supply chain

* Corresponding author. Tel.: +982177240541

E-mail: mmirzaee@ind.iust.ac.ir(M. Mirzaee) 
performance improvement and in this case, the contracts allocated a large number of research paper to themselves as a coordination mechanism. Cachon (2003) performed a comprehensive review on coordination literature with contracts approach and evaluated different scenarios in newsvendor problem under different conditions. Tsay et al. (1998) established another study on various contract types and tried to determine their conceptual frameworks in order to classify the literature on supply chain coordination. Most primary researches in this field considered the demands as determined or fixed. Most of the times, the amount of advertising and customer service providing have important roles in supply chain and attracting demands which are mostly proposed in insurance industries and supply chains with fixed price level for the end customer. A retailer can affect the products demand through advertising, employing new sales representatives, market development and these activities can increase demand. All of these activities are costly, thus encouraging supply chain members to increase the amount of advertising is an important issue that has been mentioned in some papers. Most of the articles that considered the advertising effect used a two-level supply chain with one supplier and one retailer.

Taylor (2002) explained that the chain can be coordinated through a combination of sales rebate and buyback contracts. He et al. (2009) studied the supply chain coordination with demand dependency on sales advertisement and price using the changes in contracts. They explained that none of the traditional buyback and revenue sharing contracts could coordinate the supply chain and we can only achieve complete supply chain coordination through a combination of these contracts and use of penalty contract. Cachon and Lariviere (2005) demonstrated that the revenue sharing contract cannot coordinate the supply chain and proposed a simple quantity discount contract for coordination. Netessin and Rudi (2000) suggested combined revenue and cost sharing contracts to coordinate a supply chain.

Quansheng et al. (2010) also demonstrated that it is possible to coordinate a supply chain with advertising dependent demand through using quantity flexible and advertising cost sharing contracts. Kaya (2011) assessed the supply chain contracts with advertising and cost dependent demand and advertising effect in two cases that both retailer and manufacturer allocate separate costs for advertising. Qinghua et al. (2008) reviewed a supply chain with price and advertising dependent demand such that the manufacturer once alone and once with retailer performs advertising actions and showed that using the revenue sharing contracts, this supply chain can be coordinated. Xie and Wei (2009) considered a supply chain with price and advertising dependent demand and assessed this supply chain coordination in two cases: partnership and non-partnership advertising. They explained that in partnership, advertising case a better coordination could be achieved among supply chain members and the wholesale price for retailers would be decreased. Shi-Zhen and Juan (2009) considered a supply chain with fixed price and two decision variables for retailer: order quantity and advertising level. They used buyback contract and advertising cost sharing and showed the situation the supply chain will be coordinated.

Few articles evaluated the competition effect between upstream or downstream members (Choi, 1996; Parlar \& Weng, 2006). They supposed that the two retailers have an equal competitive power in their exclusive market. Competition on price has been studied on some other articles such as Yao et al. (2008) and Wong and Leung (2008) but competition on advertising between retailers never has been evaluated. Yu et al. (2009) analyzed the production supply chain vendor managed inventory 
with one manufacturer and several retailers with advertising and price dependent demand rate. They used the stackelberg game for decision making.

In this paper, retailers decide on price and advertising issues after the policy determination of the manufacturer. The manufacturer determines the order quantity for retailers and the competition effect between retailers have not considered here. In section 2, the assumptions and conditions under which the model is defined, is shown. In section 3, non-coordinated decentralized supply chain is assessed and in this case the optimal parameters and the expected benefit for all members and the total chain are identified. Section 4 examines the centralized supply chain to determine the optimal supply chain parameters. These parameters will be used in section 5 for the decentralized supply chain coordination in order to encourage the retailer to set the optimal supply chain parameters through using coordinator contracts. In this section it is shown that in addition to establishing the win-win situation, supply chain coordination will be established. Section 6 shows a numerical example of using the proposed method for coordinating the supply chain and also the competition effect between retailers is analyzed. Finally, the conclusion is provided in Section 7.

\section{Assumptions and model parameters}

It is assumed that all supply chain members are in one market, the demand faced by each retailer is probable and dependent to the amount of advertising and all retailers compete with each other on advertising. The Manufacturer and retailers behaviors are based on stackelberg game. First the manufacturer determines its strategy and then the retailers based on the wholesale price that the manufacturer determines will determine the order quantity and advertising level to optimize their expected profit. Based on the order quantity of each retailer, enough goods will be produced by the manufacturer and they are delivered to retailers before the start of the selling season. It is assumed that the manufacturer has an unlimited capacity.

$X_{i}$ is the real demand faced by $i^{\text {th }}$ retailer that could be written as $X_{i}=D_{i}+\varepsilon_{i}$ where $D_{i}$ is the identified and linear demand which is dependent on advertising. We have $\mathrm{D}_{\mathrm{i}}=\mathrm{a}_{\mathrm{i}}+\mathrm{b}_{\mathrm{i}} \mathrm{e}_{\mathrm{i}}-\mathrm{k}_{\mathrm{i}} \mathrm{e}_{\mathrm{j}}$ and $\varepsilon_{\mathrm{i}}$ is the random and advertising independent factor which is defined in limited range of $\left[\mathrm{A}_{\mathrm{i}}, \mathrm{B}_{\mathrm{i}}\right]$ for $\mathrm{i}=\{1,2\}, \mathrm{j}=3-\mathrm{i}$ and Also $a_{i}$ is the initial demand, $b_{i}$ is the demand sensitivity of ith retailer for its own advertising and $k_{i}$ is the demand sensitivity of $i^{\text {th }}$ retailer for its rival's advertising. It is assumed that $a_{i}, b_{i}>0$ and $b_{i}>k_{i}$, which means that each retailer demand mostly depends on its own advertising than its rivals which seems to be reasonable. To ensure that the demand rate for any advertising level is positive, $A_{i}>-a_{i}$ condition must be satisfied. It is assumed that the random demand factor has a probability density function $\mathrm{f}($.$) with a continuous derivate \mathrm{f}$ (.) and a continuous cumulative distribution function with a strictly increasing inverse, $F\left(\right.$.). Also it is assumed that the ith retailer spends $g_{i}\left(e_{i}\right)$ advertising cost for the $\mathrm{e}_{\mathrm{i}}$ advertising level which is an increasing function based on the advertising level.

The below parameters are used in our model:

$a_{i}$ : The initial order quantity for ith retailer,

$b_{i}$ : The demand sensitivity of ith retailer on its own advertising,

$\mathrm{k}_{\mathrm{i}}$ : The demand sensitivity of ith retailer on its rival's advertising,

$\mathrm{S}_{\mathrm{i}}$ : The shortage cost per unit for the ith retailer,

$\mathrm{C}$ : Manufacturer cost per unit,

$\mathrm{X}_{\mathrm{i}}$ : The real demand that the ith retailer faces (where $\mathrm{X}_{\mathrm{i}}=\mathrm{D}_{\mathrm{i}}+\varepsilon_{\mathrm{i}}$ ), 
$\varepsilon_{\mathrm{i}}$ : The random factor of ith retailer,

$\mathrm{f}_{\mathrm{i}}($.$) : The probability density function of the random demand factor for the ith retailer,$

$\mathrm{F}_{\mathrm{i}}($.$) : The cumulative distribution of the random demand factor for the ith retailer,$ $\mathrm{g}_{\mathrm{i}}($.$) : The advertising cost function for the ith retailer,$

$\mathrm{w}_{0 \mathrm{i}}$ : The wholesale price per unit for the ith retailer under the wholesale contract,

$\mathrm{p}_{\mathrm{i}}$ : The selling price per unit which is set by the manufacturer for the end customer,

$\mathrm{e}_{\mathrm{i}}$ : Advertising level for the ith retailer,

Qi: Order quantity for the ith retailer,

$\Pi_{R i}$ : The expected profit for the ith retailer,

$\Pi_{\mathrm{M}}$ : The expected profit for the manufacturer,

$\Pi_{\mathrm{T}}$ : The expected profit for the supply chain,

The decision variables are $\mathrm{Q}_{i}$ and $\mathrm{e}_{\mathrm{i}}$ for the ith retailer and $\mathrm{w}_{\mathrm{i}}$ for the manufacturer and also two conditions $\mathrm{p}_{\mathrm{i}}>\mathrm{W}_{0 \mathrm{i}}>\mathrm{C}>0$ and $\mathrm{S}_{\mathrm{i}}>0$ are considered to make the results reasonable.

\section{Non-coordinated decentralized supply chain}

In a decentralized supply chain in non-coordinated state, both manufacturer and retailers decide under the stackelberg game to improve their profit share. This means that the manufacturer and the retailers play the leader and the follower roles, respectively. First the manufacturer determines the wholesale prices for retailers in wholesale contract and instead the retailers determine the order quantity and advertising level, simultaneously. For simplicity, we assume that the salvage value per unit is equal to zero, so that the expected profit for the $\mathrm{i}^{\text {th }}$ retailer in this case would be as follows,

$\Pi_{R i}^{d}=p_{i} \mathrm{E}\left(\min \left(X_{i}, \mathrm{Q}_{i}\right)\right)-w_{0 i} \mathrm{Q}_{i}-s_{i} \mathrm{E}\left(\left(\mathrm{X}_{i}-Q_{i}\right)^{+}\right)-g_{i}\left(e_{i}\right)$

Substituting $X_{i}=\mathrm{a}_{i}+b_{i} e_{i}-k_{i} e_{j}+\varepsilon_{i}$ and defining $\mathrm{z}_{\mathrm{i}}=\mathrm{Q}_{\mathrm{i}}-\mathrm{D}_{\mathrm{i}}$, the Eq. (1) yields the following,

$\Pi_{R i}^{d}=p_{i}\left(\left(\mathrm{a}_{i}+b_{i} e_{i}-k_{i} e_{j}\right)+\mathrm{E}\left(\min \left(z_{i}, \varepsilon_{i}\right)\right)\right)-w_{0 i}\left(\mathrm{a}_{i}+b_{i} e_{i}-k_{i} e_{j}+z_{i}\right)-s_{i} \mathrm{E}\left(\left(\varepsilon_{i}-z_{i}\right)^{+}\right)-$

$g_{i}\left(e_{i}\right)$.

Since $\left(\varepsilon_{i}-z_{i}\right)^{+}=\varepsilon_{i}-\min \left(z_{i}, \varepsilon_{i}\right)$ and $E\left(\varepsilon_{i}\right)=\mu_{i}$, the expected profit for the ith retailer can be written as:

$\Pi_{R i}^{d}=p_{i}\left(\mathrm{a}_{i}+b_{i} e_{i}-k_{i} e_{j}\right)-w_{0 i}\left(\mathrm{a}_{i}+b_{i} e_{i}-k_{i} e_{j}+z_{i}\right)-s_{i} \mu_{i}+\left(p_{i}+s_{i}\right) \mathrm{E}\left(\min \left(z_{i}, \varepsilon_{i}\right)\right)$

and we have

$$
-g_{i}\left(e_{i}\right)
$$

$\mathrm{E}\left(\min \left(z_{i}, \varepsilon_{i}\right)\right)=\int_{A_{i}}^{z_{i}} \mathrm{xf}_{\mathrm{i}}(\mathrm{x}) \mathrm{dx}+\int_{z_{i}}^{B_{i}} z_{i} \mathrm{f}_{\mathrm{i}}(\mathrm{x}) \mathrm{dx}=\int_{A i}^{B_{i}} \mathrm{xf} \mathrm{f}_{\mathrm{i}}(\mathrm{x}) \mathrm{dx}+\int_{z_{i}}^{B_{i}}\left(\mathrm{x}-z_{i}\right) \mathrm{f}_{\mathrm{i}}(\mathrm{x}) \mathrm{dx}$,

Defining $\Delta_{i}\left(z_{i}\right)=\int_{z_{i}}^{B_{i}}\left(\mathrm{x}-z_{i}\right) \mathrm{f}_{\mathrm{i}}(\mathrm{x}) \mathrm{dx}$ thus $\mathrm{E}\left(\min \left(z_{i}, \varepsilon_{i}\right)\right)$ can be written as $\mu_{i}-\Delta_{i}\left(z_{i}\right)$ that the expected profit objective function for the ith retailer is given as:

$\operatorname{maximze} \Pi_{R i}^{d}$,

where $i=\{1,2\}$ and $j=3-i$. Now by differentiating this equation with respect to $e_{i}$ we would have:

$\frac{\partial \Pi_{R i}^{d}}{\partial e_{i}}=b_{i} p_{i}-b_{i} w_{0 i}-g_{i}{ }^{\prime}\left(e_{i}\right)=0$. 
Next, by solving Eq. (6) the optimal advertising level for the ith retailer can be calculated. Similarly, differentiating Eq. (3) with respect to $z_{i}$ yields,

$\frac{\partial \Pi_{R i}^{d}}{\partial z_{i}}=\left(p_{i}+s_{i}\right)\left(1-F_{i}\left(z_{i}\right)\right)-w_{0 i}=0$.

Thus, the optimal value under the non-coordinated decentralized supply chain can be calculated as follows,

$F_{i}\left(z_{i}\right)=\frac{p_{i}+s_{i}-w_{0 \mathrm{i}}}{p_{i}+s_{i}}$

Thus the optimal values in the non-coordinated decentralized supply chain for $\mathrm{i}=\{1,2\}$ based on Eq. (6) and Eq. (8) are $e_{1}^{d}, e_{2}^{d}, z_{1}^{d}$ and $z_{2}^{d}$. The optimal order quantity for each retailer can be calculated based on equation $Q_{i}=D_{i}+z_{i}$ for $i=\{1,2\}$ and $j=3-i$ is equal to:

$Q_{i}^{d}=\mathrm{a}_{i}+b_{i} e_{i}^{d}-k_{i} e_{j}^{d}+z_{i}^{d}$

Lemma 1: the expected profit for retailers with respect to $e_{i}$ and $z_{i}$ is convex.

Proof: we form the Hessian matrix for the expected profit of retailers in the non-coordinated situation.

$\mathrm{H}_{\mathrm{Ri}}=\left[\begin{array}{cr}-g_{i}^{\prime \prime}\left(e_{i}\right) & 0 \\ 0 & -\left(p_{i}+s_{i}\right) \mathrm{f}_{\mathrm{i}}\left(z_{i}\right)\end{array}\right]$

Note that $\mathrm{f}_{\mathrm{i}}\left(z_{i}\right)$ is the probability density function and $g_{i}\left(e_{i}\right)$ is the non-decreasing function with respect to advertising levels, thus the convexity condition holds.

For a more accurate analysis, we can divide the expected profit for the manufacturer into two parts in which the expected profit for the manufacturer from the $\mathrm{i}^{\text {th }}$ retailer is equal to:

$\Pi_{M i}^{d}=\left(w_{0 i}-c\right)\left(\mathrm{a}_{i}+b_{i} e_{i}-k_{i} e_{j}+z_{i}\right)$

\section{Centralized supply chain}

In centralized supply chain, it is supposed that both manufacturer and retailers are trying to integrate the channel and to increase the total profit of the supply chain. Thus the centralized supply chain objective function to maximize the total profit of the supply chain which is consist of the summation of both the manufacturer and retailers expected profits can be calculated as follows:

$\max \Pi_{T}=\sum_{i=1}^{2} \Pi_{R i}+\Pi_{M}$

Thus, the total expected profit for the supply chain is equal to:

$\Pi_{T}=\sum_{i=1}^{2}\left[\mathrm{p}_{i} \mathrm{E}\left(\min \left(Q_{i}, \mathrm{X}_{i}\right)\right)-c Q_{i}-s_{i} \mathrm{E}\left(\left(\mathrm{X}_{i}-Q_{i}\right)^{+}\right)-g_{i}\left(e_{i}\right)\right]$

Substituting $\mathrm{X}_{\mathrm{i}}=\mathrm{a}_{\mathrm{i}}+\mathrm{b}_{\mathrm{i}} \mathrm{e}_{\mathrm{i}}-\mathrm{k}_{\mathrm{i}} \mathrm{e}_{\mathrm{j}}+\varepsilon_{\mathrm{i}}$ and $\mathrm{z}_{\mathrm{i}}=\mathrm{Q}_{\mathrm{i}}-\mathrm{D}_{\mathrm{i}}$ yields, 


$$
\begin{aligned}
\Pi_{T}=\sum_{i=1}^{2}\left[\mathrm { p } _ { i } \left(\mathrm{a}_{i}\right.\right. & \left.+b_{i} e_{i}-k_{i} e_{j}+\mathrm{E}\left(\min \left(z_{i}, \varepsilon_{i}\right)\right)\right)-\mathrm{c}\left(\mathrm{a}_{i}+b_{i} e_{i}-k_{i} e_{j}+z_{i}\right)-s_{i} \mathrm{E}\left(\left(\varepsilon_{i}-z_{i}\right)^{+}\right) \\
& \left.-g_{i}\left(e_{i}\right)\right]
\end{aligned}
$$

By differentiating the total expected profit, Eq. (13), for the supply chain with respect to $\mathrm{e}_{\mathrm{i}}$ we have:

$\frac{\partial \Pi_{T}}{\partial e_{i}}=b_{i}\left(p_{i}-c\right)-g_{i}{ }^{\prime}\left(e_{i}\right)+k_{i}\left(\mathrm{c}-p_{j}\right)=0$.

and similarly by differentiating with respect to $\mathrm{z}_{\mathrm{i}}$ we have:

$\frac{\partial \Pi_{T}}{\partial z_{i}}=\left(p_{i}+s_{i}\right)\left(1-F_{i}\left(z_{i}\right)\right)-c=0$,

and $z_{\mathrm{i}}$ can be calculated by the following,

$F_{i}\left(z_{i}\right)=\frac{p_{i}+s_{i}-c}{p_{i}+s_{i}}$.

Therefore, we can calculate the optimal order quantity and advertising level based on Eq. (14) and Eq. (16) and these optimum values in this case are called $e_{1}^{c}, e_{2}^{c}, Q_{1}^{c}$ and $Q_{2}^{c}$ where the optimal order quantity in this case for $i=\{1,2\}$ and $j=3-i$ can be calculated as follows,

$Q_{i}^{c}=\mathrm{a}_{i}+b_{i} e_{i}^{c}-k_{i} e_{j}^{c}+z_{i}^{c}$.

Lemma 2: The total expected profit for the supply chain with respect to $\mathrm{e}_{\mathrm{i}}$ and $\mathrm{z}_{\mathrm{i}}$ is convex.

Proof: we form the Hessian matrix for the total expected profit of the supply chain.

$\mathrm{H}_{\mathrm{T}}=\left[\begin{array}{cr}-g_{i}^{\prime \prime}\left(e_{i}\right) & 0 \\ 0 & -\left(p_{i}+s_{i}\right) \mathrm{f}_{\mathrm{i}}\left(z_{i}\right)\end{array}\right]$,

which is exactly the same as the Hessian matrix of the expected profit for retailers in non-coordinated condition and since $\mathrm{f}_{\mathrm{i}}\left(z_{i}\right)$ is the probability density function and $g_{i}\left(e_{i}\right)$ is a non-decreasing function with respect to advertising levels, thus the convexity condition holds.

\section{Coordinated decentralized supply chain}

In this section for establishing supply chain coordination, two proposed quantity discount and advertising cost sharing contracts are used. The manufacturer encourages the retailers by offering the quantity discount contract to increase their order quantity. Thus, in this case retailers accept to investigate more on advertising and because demands on the amount of advertising, the advertising cost sharing contract will be used. Based on this contract, the manufacturer pays a part of the retailers' advertising cost so the retailers will be encouraged to increase their advertising rates and this consequently will increase customer demand. Therefore, by using this combined contract it is shown that the supply chain coordination will be established. The expected profit for retailers in this case would be equal to:

$$
\begin{aligned}
\Pi_{R i}^{c}=p_{i}\left(\mathrm{a}_{i}+\right. & \left.b_{i} e_{i}^{c}-k_{i} e_{j}^{c}\right)-w_{i}\left(\mathrm{a}_{i}+b_{i} e_{i}^{c}-k_{i} e_{j}^{c}+z_{i}^{c}\right)-s_{i} \mu_{i}+\left(p_{i}+s_{i}\right) \mathrm{E}\left(\min \left(z_{i}^{c}, \varepsilon_{i}\right)\right) \\
& -\theta_{i} g_{i}\left(e_{i}^{c}\right),
\end{aligned}
$$

where $\mathrm{w}_{\mathrm{i}}$ is the wholesale price under the quantity discount contract and $\theta_{\mathrm{i}}$ is the advertising cost share for the $i^{\text {th }}$ retailer and obviously $1-\theta_{i}$ is the advertising cost share for the manufacturer. The expected profit for the manufacturer from the $\mathrm{i}^{\text {th }}$ retailer can be calculated as: 
$\Pi_{M i}^{c}=\left(w_{i}-c\right)\left(\mathrm{a}_{i}+b_{i} e_{i}^{c}-k_{i} e_{j}^{c}+z_{i}^{c}\right)-\left(1-\theta_{i}\right) g_{i}\left(e_{i}^{c}\right)$.

However, the manufacturer and the retailers will accept this coordinator contract when their expected profits become higher or at least equal to the non-coordinated state. So from the perspective of the retailer, the following condition must hold,

$\Pi_{R i}^{c}\left(Q_{i}^{c}, e_{i}^{c}\right) \geq \Pi_{R i}^{d}\left(Q_{i}^{d}, e_{i}^{d}\right)$

and therefore we have,

$w_{i} \leq \frac{1}{Q_{i}^{c}}\left[p_{i}\left(\mathrm{E}\left(\min \left(Q_{i}^{c}, X_{i}^{c}\right)\right)-\mathrm{E}\left(\min \left(Q_{i}^{d}, X_{i}^{d}\right)\right)\right)-s_{i}\left(E\left(X_{i}^{c}-Q_{i}^{c}\right)^{+}-E\left(X_{i}^{d}-Q_{i}^{d}\right)^{+}\right)+\right.$

$\left.\left(1-\theta_{i}\right) g_{i}\left(e_{i}^{c}\right)+w_{0 i} Q_{i}^{d}\right]$.

Similarly, from the perspective of the manufacturer, the following condition must hold,

$\Pi_{M i}^{c}\left(Q_{i}^{c}, e_{i}^{c}\right) \geq \Pi_{M i}^{d}\left(Q_{i}^{d}, e_{i}^{d}\right)$

Therefore, we have:

$w_{i} \geq \frac{1}{Q_{i}^{c}}\left[c Q_{i}^{c}+\left(1-\theta_{i}\right) g_{i}\left(e_{i}^{c}\right)+\left(w_{0 i}-c\right) Q_{i}^{d}\right]$

Thus if the coordinator contract establishes the Eq. (21) and Eq. (23) conditions, always both the manufacturer and the retailers will benefit from it. In fact, by setting the wholesale price in the range of $\left(w_{\text {iMin }}, w_{\text {iMax }}\right)$ it is possible for the manufacturer to establish the wholesale price in this range for coordination.

In this section, we propose the Nash complete equilibrium model to evaluate the supply chain performance. In this case, we have $w_{i}=w_{i \text { Max }}$ and based on this, we calculate the expected profits for both the manufacturer and the retailers. The total expected centralized supply chain profit under the Nash complete equilibrium model will be equal to the summation of both the manufacturer and retailers profits. When $w=w_{i \text { Max }}$, the increase in system profit because of the coordination will be equal to the increase in the manufacturer's profit. The increase in the manufacturer profit can be shared through negotiation by means of mutual agreement sharing programs. Therefore, the model will achieve the complete supply chain coordination and also the win-win condition for all the supply chain members will be established.

\section{Numerical example}

In this section, a numerical example is presented to describe the coordination model and verify the acceptable performance of the coordinator contracts. We assume that the demands for the retailers are $X_{i}=100+10 e_{i}-3 e_{j}+\varepsilon_{i}$ for $\mathrm{i}=\{1,2\}$ and $\mathrm{j}=3-\mathrm{i}$ and $\varepsilon_{\mathrm{i}}$ follows a uniform distribution within the interval of $[0,5]$. The other parameters are defined as follows:

$s_{i}=2, c=5, p_{i}=25, \theta_{i}=0.7, w_{0 i}=20$ 
Also, we consider the cost function for the $i^{\text {th }}$ retailer as $g_{i}\left(e_{i}\right)=\frac{e_{i}^{2}}{2}$. Using the MATLAB 7 software, the optimal values and expected profits are shown in Tables 1 and Table 2.

\section{Table 1}

The optimal values

\begin{tabular}{lcc}
\hline & Supply chain non-coordinated & Coordinated supply chain \\
\hline $\mathrm{Z}_{\mathrm{i}}$ & 1.29 & 4.07 \\
$\mathrm{Q}_{\mathrm{i}}$ & 416.29 & 1084.1 \\
$\mathrm{~W}_{\mathrm{i}}$ & 20 & 16.79 \\
$\mathrm{e}_{\mathrm{i}}$ & 45 & 140 \\
\hline
\end{tabular}

Table 2

The optimal expected profits

\begin{tabular}{lcc}
\hline & Supply chain non-coordinated & Coordinated supply chain \\
\hline$\Pi_{\mathrm{Ri}}$ & 964.76 & 1003.1 \\
$\Pi_{\mathrm{Mi}}$ & 6244.4 & 9910.9 \\
$\Pi_{\mathrm{T}}$ & 14418.32 & 21828 \\
\hline
\end{tabular}

According to Table (1), it is observed that in the coordinated case the wholesale price for retailers is lower than the one in the non-coordinated form. Thus, both the order quantity of the retailers and the advertising level are increased and in this case according to Table 2 the expected profit for the retailers, the manufacturer and the whole supply chain are increased. Therefore, we can conclude that the combined contract is efficient.

\subsection{The competition effect}

In this section, we will examine the competition effect between retailers in the amount of advertising. The demand that the ith retailer is faced can be written as $X_{\mathrm{i}}=a_{\mathrm{i}}+\left(b_{\mathrm{i}}-k_{\mathrm{i}}\right) e_{i}-k_{\mathrm{i}}\left(e_{j}-e_{i}\right)+\varepsilon_{i}$ so we can measure the competition effect through changing the $\mathrm{k}_{\mathrm{i}}$ value while fixing the $\mathrm{b}_{\mathrm{i}}-\mathrm{k}_{\mathrm{i}}$ value. We used the method suggested by Yao (2008) and Tsay and Agrawal (2000) to examine the competitive factor. Thus, the following results will be deducted from the Tables 3 and Table 4.

\section{Table 3}

The competition effect in non-coordinated supply chain

\begin{tabular}{lcccccccc}
\hline $\mathrm{b}_{\mathrm{i}}-\mathrm{k}_{\mathrm{i}}$ & $\mathrm{b}_{\mathrm{i}}$ & $\mathrm{k}_{\mathrm{i}}$ & $\mathrm{Q}^{\mathrm{d}}{ }_{\mathrm{i}}$ & $\mathrm{e}^{\mathrm{d}}{ }_{\mathrm{i}}$ & $\Pi_{\mathrm{Ri}}$ & $\Pi_{\mathrm{Mi}}$ & $\Pi_{\mathrm{T}}$ & $\mathrm{E}_{\mathrm{f}}$ \\
\hline 7 & 9 & 2 & 416.29 & 45 & 964.76 & 6244.44 & 14418.42 & 0.1544 \\
7 & 10 & 3 & 451.29 & 50 & 902.26 & 6769.44 & 15343.42 & 0.1332 \\
7 & 11 & 4 & 486.26 & 55 & 814.76 & 7294.44 & 16218.42 & 0.1116 \\
7 & 12 & 5 & 521.29 & 60 & 702.26 & 7819.44 & 17043.42 & 0.0898 \\
9 & 10 & 1 & 551.29 & 50 & 1402.26 & 8269.44 & 19343.42 & 0.1695 \\
9 & 11 & 2 & 596.29 & 55 & 1364.76 & 8944.44 & 20618.42 & 0.1525 \\
9 & 12 & 3 & 641.29 & 60 & 1302.26 & 9619.44 & 21843.42 & 0.1353 \\
9 & 13 & 4 & 686.29 & 65 & 1214.76 & 10294.44 & 23018.42 & 0.1180 \\
\hline
\end{tabular}


Table 4

The competition effect in coordinated supply chain

\begin{tabular}{lllllllll}
\hline $\mathrm{b}_{\mathrm{i}}-\mathrm{k}_{\mathrm{i}}$ & $\mathrm{b}_{\mathrm{i}}$ & $\mathrm{k}_{\mathrm{i}}$ & $\mathrm{Q}_{\mathrm{i}}^{\mathrm{c}}$ & \multicolumn{1}{c}{$\mathrm{e}^{\mathrm{c}}{ }_{\mathrm{i}}$} & \multicolumn{1}{c}{$\Pi_{\mathrm{Ri}}$} & $\Pi_{\mathrm{Mi}}$ & $\Pi_{\mathrm{T}}$ & $\mathrm{E}_{\mathrm{f}}$ \\
\hline 7 & 9 & 2 & 1084.1 & 140 & 1065.58 & 9848.35 & 21827.88 & 0.1081 \\
7 & 10 & 3 & 1084.1 & 140 & 1003.08 & 9910.85 & 21827.88 & 0.1012 \\
7 & 11 & 4 & 1084.1 & 140 & 915.58 & 9998.35 & 21827.88 & 0.0915 \\
7 & 12 & 5 & 1084.1 & 140 & 803.08 & 10110.85 & 21827.88 & 0.0794 \\
9 & 10 & 1 & 1724.1 & 180 & 1503.08 & 15810.85 & 34627.88 & 0.0950 \\
9 & 11 & 2 & 1724.1 & 180 & 1465.58 & 15848.35 & 34627.88 & 0.0924 \\
9 & 12 & 3 & 1724.1 & 180 & 1403.08 & 15910.85 & 34627.88 & 0.0881 \\
9 & 13 & 4 & 1724.1 & 180 & 1315.58 & 15998.35 & 34627.88 & 0.0822 \\
\hline
\end{tabular}

When competition is intensified, advertising rates and order quantity will be increased. Also the expected profit for the retailers and the manufacturer will be reduced and increased respectively and we can conclude that the intensified competition will not benefit the retailers and vice versa the manufacturer will receive more profits from this intensified competition between the retailers and also the total supply chain profit will be increased, simultaneously. Therefore, intensifying the competition will improve the performance of the channel. Intensifying the competition, $\mathrm{E}_{\mathrm{f}}$ which is defined as $\mathrm{E}_{\mathrm{f}}=\Pi_{\mathrm{Ri}} / \Pi_{\mathrm{Mi}}$ will be decreased and as mentioned this shows that the manufacturer will achieve more advantages than the retailers.

\section{Conclusion}

In this research, a two-level supply chain with one manufacturer and two retailers have been studied in which the retailers are faced with probable advertising rate dependant demand. In this study, we used a combined quantity discount and advertising cost sharing contracts to coordinate the supply chain and it is shown that the supply chain coordination will be fully established which means that the decisions of the supply chain members will be made according to the combined contract so that the total supply chain profit will be maximized. In addition, the win-win conditions are considered for the supply chain members where the supply chain members will achieve more profit by accepting the coordinator contract and this can encourage them to accept it. Here, it is shown that the competition between supply chain members will affect the total chain profit. When this competition intensified, both the total supply chain and the manufacturer benefits will be increased but the retailers will suffer from this condition.

Other factors including the price can be considered as decision variables in model development. In this model, it is assumed that the price is fixed and is determined by the manufacturer. In addition, the price can be considered as a competitive factor between retailers and in this case, the model will become more complicated. Besides, a condition with several manufacturers with a competitive factor among them to sell their products to the retailers has not been considered in this model and can be used as one of the important future research topics in this field.

\section{Acknowledgment}

The authors would like to thank the anonymous referees for their constructive comments on earlier version of this work. 


\section{References}

Hosseini, S. M. (2008). Quantitative analysis of the bullwhip effect in supply chain using moving average, Exponential smoothing and $\mathrm{ARCH}, \mathrm{GARCH}$ forecast. Master thesis in Industrial Engineering, University college of Boras, Sweden.

Cachon, G. P. (2003). Supply chain coordination with contracts. Handbook in Operations Research \& Management Science, 11.

Tsay, A., Nahmias, S., \& Agrawal, N. (1998). Modeling supply chain contracts: a review. In: S. Tayur, R. Ganeshan, M. Magazine (eds.), Quantitative Models for Supply Chain Management, Boston, Kluwer.

Taylor, T. (2002). Coordination under channel rebate with sales effort effect. Management Science, 48, 992-1007.

He, Y., Zhao, X., Zhao, I., He. J. (2009). Coordinating a supply chain with effort and price dependent stochastic demand. Applied Mathematical Modeling, 33, 2777-2790.

Cachon, G. P., \& Lariviere, M. A. (2005). Supply Chain Coordination with Revenue-Sharing Contracts: Strengths and Limitations. Management Science, 51, 30-44.

Netessin, S., \& Rudi, N. (2000). Supply chain structures on the internet: marketing-operation coordination. University of Pennsylvania, Working paper, Philadelphia, Pa.

Quansheng, L., Zhiyuan, S., DongQing, J., \& XiaoGuang, Z. (2010). Two-stage supply chain coordination with effort cost sharing. E-business and information system security (EBISS), International Conference on Wuhan, 22-23, 1-3.

Kaya, O. (2011). Outsourcing vs. in-house production: a comparison of supply chain contracts with effort dependent demand. Omega, 39, 168-178.

Qinghua, P., Xiaoqian, D., Dong, D., \& Chao, C. (2008). Supply chain coordination under price and effort-dependent demand with revenue sharing contract. $8^{\text {th }}$ International Conference on Wireless Communications, Networking and mobile computing, Dalian, 12-14 Oct, pp. 1-4.

Xie, J., \& Wei, J.C. (2009). Coordinating advertising and pricing in a manufacturer-retailer channel. European Journal of Operational Research, 197, 785-791.

Shi-Zhen, B., \& Juan, N. (2009). Research on buy-back contract with sales effort cost sharing. Control and Decision conference, Guilin, 17-19 June, 1917-1921.

Choi, S.C. (1996). Price competition in duopoly common retailer channel. Journal of Retailing, 72 , 117-134.

Parlar, M., \& Weng, Z. K. (2006). Coordinating pricing and production decision in presence of price competition. European Journal of Operational Research, 170, 211-227.

Yao, Z., Leung, S.C.H., \& Lai, K.K. (2008). Manufacturer's revenue-sharing contract and retail competition. European Journal of Operational Research, 186, 637-651.

Wong, W. K., Qi, J., \& Leung, S. Y. S. (2009). Coordinating supply chain with sales rebate contracts and vendor-managed inventory. International Journal of Production Economics, 120, 151-161.

Yu, Y., Huang, G.Q., \& Liang, L., (2009). Stackelberg game-theoretic model for optimizing advertising, pricing and inventory policies in vendor managed inventory (VMI) production supply chains. Computers \& Industrial Engineering, 57, 368-382.

Tsay, A.A, \& Agrawal, N. (2000). Channel dynamics under price and service competition. Manufacturing \& Service Operations Management, 2, 372-391. 